\title{
Familia, estrategias de reproducción social y comercio de exportación en Tucumán, Argentina, 1780-1820. Una aproximación a partir de la familia Posse/
}

\author{
Family, social reproduction and strategies of export \\ in Tucumán, Argentina, 1780-1820. \\ An approach from the Posse family
}

Francisco Bolsi

Instituto Superior de Estudios Sociales (ISES)/CONICET

Con el advenimiento del siglo XXI, los historiadores latinoamericanos debatieron nuevamente acerca de las posturas historiográficas que analizaron la transición del período tardo colonial al proceso de revolución e independencia a principio del siglo XIX, atendiendo al impacto de estos sucesos en las diversas regiones que integraban el espacio colonial hispanoamericano. Estos debates generaron la necesidad de indagar cómo atravesó la ciudad de San Miguel de Tucumán este proceso, a partir del estudio de una familia representativa de la elite local, los Posse, entre 1780 y 1820. Por este motivo, se centro la atención en la organización familiar, las estrategias de reproducción social y las actividades comerciales efectuadas por Manuel Posse, comerciante peninsular, en Tucumán.

Palabras Clave: Familia; Parentesco; Comercio.

With the advent of the 21st century American historians discussed again about the historiographical positions that discussed the transition from the late colonial period to the process of revolution and independence at beginning of the 19th century, in response to the impact of these events in the various regions comprising the Hispano-American colonial space. These discussions resulted in the need to explore how the city of San Miguel de Tucumán went through this process, from the study of a family representative of the local elite, the Posse, between 1780 and 1820. For this reason, will centre attention on the family organization, social reproduction strategies and activities carried out by Manuel Posse, peninsular merchant,Tucumán.

KeYwORDS: Family; Kinship; Trade. 


\section{Introducción}

El bicentenario del proceso de revolución e independencia en América Latina generó una revisión historiográfica de los antecedentes de estos acontecimientos vinculados con las reformas borbónicas, el proceso de atlantización de la economía, la expulsión de los jesuitas, la ilustración criolla y las posteriores experiencias de organización política devenidas de la desintegración de los territorios virreinales. Estos debates se centraron en analizar las causas profundas e inmediatas que originaron el inició de la revolución, las consecuencias de la guerra y la experiencia política de los sucesivos gobiernos criollos, entre otros temas. ${ }^{1}$ En la Argentina, el estudio del proceso de revolución e independencia generó una abundante producción historiográfica entre 1990 y 2010, que fue difundida en jornadas, congresos y publicaciones, que ahondaron en la interpretación de la marcha de la revolución en el Río de la Plata, a partir de las nuevas posturas propuestas desde la historia política vinculadas con la conformación del pueblo, del ciudadano y los aportes de la historia social, a partir del estudio del bajo pueblo y su participación en las milicias revolucionarias. ${ }^{2}$ En Tucumán específicamente, la producción académica fue constante y la conmemoración del bicentenario generó por parte de los historiadores locales el replanteamiento de posturas historiográficas tradicionales. ${ }^{3}$

Uno de los tópicos que se encuentra estrechamente ligada al caso tucumano fue la guerra. El territorio de la Intendencia de Salta del Tucumán se transformó, en el transcurso del proceso revolucionario, en un espacio en donde dirimieron sus fuerzas las huestes patriotas y realistas en la batalla de Tucumán de $1812 .{ }^{4}$ En todo caso, si bien la guerra fue una característica inherente al proceso de revolución e independencia no resultó la preocupa-

1 En Latinoamérica la producción historiográfica es sumamente extensa pero sólo se citó algunos de ellos, véase: Gilbert y Nugent, 2002; Timothy, 2003; Annino, 2006; Chust y Serrano (eds.), 2007; Aljovín y Jacobsen (eds.), 2007.

2 En Argentina la producción historiográfica es abundante. Véase: Goldman, 1999, 21-69; Garavaglia, 2003, 153-187; Herrero, 2004 y 2007; Di Meglio, 2005; Schmit, 2004.

3 La producción historiográfica local en los últimos veinte años fue constante. Sin embargo, sólo se citó aquellos trabajos más representativos para la elaboración de esta publicación: Nicolini, 1994, 47-79; Tío Vallejo, 2001; López, 2003, 2008 y 2009; Iramain, 2005; Leoni Pinto, 2008. Los nuevos planteamiento desde la historia política, social y económica referidos a la revolución fueron de los siguientes autores: Macias y Parolo, 2010; Bolsi, 2010; Davio, 2011, 93-124.

4 Un elemento insoslayable del proceso revolucionario fue el tema de la guerra. En este sentido, la producción historiográfica dio cuenta del peso económico que generó el conflicto en los territorios que fueron epicentro del mismo y sus zonas de influencia. Para el caso tucumano, véase: Leoni Pinto, 1973, 165-177 y 2008; Mata, 1999; Gil Montero, 2004, 9-36; Schmit, 2004. 
ción central de esta investigación. Más bien sirvió como pretexto para abordar el análisis de la elite tucumana y de una familia en particular.

En este trabajo se ha realizado una aproximación al comercio de exportación y se han analizado las estrategias familiares y de reproducción social que implementó la familia Posse entre 1780-1820. Se trató específicamente este período por tres motivos. 1) Fue una coyuntura que ocasionó un cambio en las relaciones de poder al interior de la elite local tanto por las reformas borbónicas como por las implicancias del proceso revolucionario. Por este motivo, se organizó este trabajo a partir de un análisis década por década, con la finalidad de observar las transformaciones que se suceden en este período de transición. 2) El fundador de esta familia integró la corriente migratoria borbónica que se transformó en el territorio americano en la nueva elite del período tardo colonial. Se indagaron específicamente las estrategias matrimoniales que implementó el peninsular y posteriormente sus hijos, debido que las mismas junto a las actividades económicas y el posicionamiento político permitieron a esta familia atravesar este período de transición. 3) Se analizaron los circuitos comerciales de exportación, identificando los destinos y la relación entre rutas comerciales y lazos de parentesco. En este sentido, se realizó una aproximación a las actividades comerciales desarrolladas por el peninsular a partir del comercio de exportación con la finalidad de obtener un panorama de las transacciones mercantiles. ${ }^{5}$

Para este trabajo se analizaron diversas fuentes. En el Archivo Histórico de Tucumán (a partir de ahora AHT) se indagó el Boletín Genealógico de Tucumán con la finalidad de obtener información referida al origen de las ramas fundadora de los Posse. Se analizó la Sección Judicial Civil (SJC) en donde se registraron los testamentos referidos a la familia en cuestión, a partir de los cuales se observó las hijuelas que recibieron cada uno de los descendientes, lo que permitió su posicionamiento al momento de los enlaces matrimoniales. Asimismo, se indagó la Sección Administrativa (SA) donde se registraron los cargos públicos ocupados por los integrantes de la familia Posse en el período estudiado. Se complementó con información extraída de las Actas del Cabildo de la ciudad, que aportaron nuevos datos referidos al desempeño de los integrantes de la familia en cuestión. En este mismo lugar, se relevó la Sección de Hacienda que contiene los Cuadernos de Tomas de Razón (TR) expedidas por la Tesorería de

5 Cabe aclarar que el propósito de este trabajo no se centra en realizar un estudio minucioso del comercio de exportación sino una aproximación que de cuenta de las actividades comerciales y los circuitos en donde participó Manuel Posse. 
Tucumán, la sección de Comprobantes de Contaduría (CC) y la sección Oficios Varios (OV) en donde se registraron las guías de exportación hacía Buenos Aires efectuadas por la familia Posse. La prospección de las fuentes se completó para el período 1786/1809 mientras que para la década revolucionaria sólo se realizó una exploración parcial entre 1810 y 1814 debido a que la búsqueda de los datos resultó dificultosa. Esto se debió principalmente a que las secciones de CC y de OV no fueron indexadas y la búsqueda de información se remitió a una exploración hoja por hoja. A pesar de ello, la información obtenida permitió un panorama lo suficientemente acabado para realizar un análisis de la familia Posse.

\section{La inmigración borbónica a fines del siglo XVIII. Orígenes de la red de parentesco e inserción social de los hermanos Posse en Buenos Aires y Tucumán}

En la segunda mitad del siglo XVIII, el rey Carlos III implementó las reformas borbónicas con el propósito de reforzar el control administrativo sobre los territorios coloniales. La elite americana se adaptó a los nuevos requerimientos de la Metrópoli implementando diversas estrategias de reproducción social y fortaleciendo su red de relaciones, lo que aseguró su continuidad en el contexto local. ${ }^{6}$

Estas transformaciones suscitaron la inmigración de numerosos comerciantes peninsulares hacía el territorio americano, luego de la aprobación del Tratado de Libre Comercio de 1774, en búsqueda de nuevas oportunidades económicas.

Por este motivo, se consideró al concepto de red como una herramienta fundamental para analizar y comprender el comportamiento de las familias de la elite tucumana en este período de transición entre la colonia y el período revolucionario. ${ }^{7}$ Los individuos que integraban las redes se desen-

6 En el caso tucumano, uno de los estudios pioneros fue el de Ana María Bascary, que indagó la historia de familia en el Tucumán tardo colonial. A partir de allí, otros investigadores se preocuparon por esta temática Véase: Bascary, 1994, 1999; López, 2004; Iramain, 2005; Bolsi, 2008.

7 El concepto de red o también entendido como social networks, fue ampliamente estudiado. En este sentido, se entendió por red al conjunto de vínculos sociales llevados a cabo por una o más personas con la finalidad de cumplir un propósito específico, en el cual se puede identificar una cadena de mando o una cohesión entre sus miembros que se caracteriza en algunos casos por prestar apoyo, protección política y mantener solidaridades internas. Del mismo modo, una característica inherente es su dinamismo debido a que la red está determinada por las motivaciones particulares que aportan los individuos que participan de la misma. Véase: Bertrand, 1999, 107-135; Ponce Leiva y Amadori, 2008, 15-42. 
volvían dentro de un marco normativo, pero en la mayoría de las ocasiones su accionar estaba mucho más influenciado por sus objetivos personales, sus capacidades y su acceso a la información. ${ }^{8}$ En todo caso, la reciprocidad entre los miembros se condicionó a los buenos resultados conseguidos en la articulación de la red por los intermediarios porque si esto no se lograba, el conflicto y las fricciones se transformaban en una práctica recurrente. Otro elemento directamente relacionado con el concepto de red, eran las estrategias familiares que utilizaban los enlaces matrimoniales como mecanismos que vinculan los grupos, en diferentes espacios como el local, el regional y el extrarregional.

En Tucumán, en el período en estudio, las familias de la elite tenían una composición determinada por diferentes variables que tenía en algunas ocasiones como eje la institución familiar y en otras, a personas que pertenecían al circulo extrafamiliar que se emplazaban en determinados espacios de poder. Las reformas borbónicas provocaron una reformulación de las estrategias de reproducción social por parte algunas familias de la elite, quienes posteriormente se transformaron en la nueva elite del periodo tardo colonial.

En este contexto se insertaron los hermanos Posse, quienes formaron parte de la corriente migratoria borbónica. Manuel, el fundador de línea familiar en Tucumán, nació en la villa de Camariñas (la Coruña) en 1753 y su hermano Gerardo nació en 1756 en el mismo lugar. Ambos eran hijos de Domingo Antonio Posse y de Ana María Blanco de Martínez. ${ }^{9}$ De acuerdo con el genealogista gallego Crespo Pozo, este apellido pertenece a un antiguo linaje familiar, con escudo y casa solar radicada en Santa María de Sada, en las inmediaciones de la Coruña, sitio en el que ejercían señorío y jurisdicción. Esta región estaba relacionada con las actividades comerciales entre la zona de la Coruña y el vecino país de Portugal. ${ }^{10}$

Los hermanos, en un primer momento, se establecieron en 1776 en la ciudad de Montevideo donde realizaron, de acuerdo a los datos aportados

8 Moutoukias, 2000.

9 Archivo Parroquial de Camariñas (en adelante APC), La Coruña, España, Libro de Bautismos n. ${ }^{\circ} 1,119$.

10 Crespo Pozo, 1977, 237. El padre de estos jóvenes, según el catastro del Marqués de Ensenada - levantado en 1753- poseía un galeón para el comercio de cabotaje con los puertos portugueses y gallegos. Además de esta propiedad poseía casas y cultivos. Fue señalado como uno de los hombres de fortuna de la región en donde vivían. Archivo del Reino de Galicia, (en adelante AG) Catastro del Márquez de la Ensenada; San Jorge de Buria y Villa de Camariñas (Ayuntamiento de Vimianzo), año 1753 -Real Legos, 510- 512. 
por la tradición familiar, diversas transacciones comerciales vinculadas con la importación de efectos de ultramar. Poco tiempo después, se trasladaron a Buenos Aires, en donde residía su tío Tomás Posse y Collins, quien se desempeñaba como comerciante de la plaza local. ${ }^{11}$

En todo caso, las estrategias que implementaron los Posse fueron diferentes. Por un lado, en 1792, Gerardo contrajo matrimonio con su prima María Insúa y Collins (hija de Tomas) lo que consolidó nuevamente los vínculos entre estos troncos familiares. ${ }^{12}$ Por otro lado, Manuel se radicó en 1779 en Tucumán y al momento de su establecimiento tenía un patrimonio cercano a los 14.310 pesos que acumuló fruto de algunas transacciones comerciales que realizó previamente a su llegada. ${ }^{13}$ El peninsular estableció vínculos económicos con comerciantes del ámbito local y capitalizó estas relaciones contrayendo matrimonio en 1783 con Águeda Tejerina y Domínguez, sobrina del Gral. Domínguez comerciante del medio local.

Águeda Tejerina era hija de Fermín Tejerina y Barreda y Teresa Domínguez. Fermín fue arrendatario de la Sisa en 1764 y recusado como Alcalde de Segundo voto en 1767 y como Gobernador de Armas en 1776, de profesión comerciante..$^{14}$ Era hijo de Francisco Texerina Barreda, quien desempeñó diversas funciones: 1783 (Alcalde de la Santa Hermandad y Regidor XXIV), 1785 (Alcalde Ordinario de 1. ${ }^{\circ}$ voto y Regidor XXIV), 1787 (Regidor XXIV y diputado del Ramo de Sisa) y 1788 (administrador de temporalidades); y de Laurencia García, naturales de Sevilla. Teresa Domínguez, esposa de Fermín, era natural de San Miguel de Tucumán, hija legitima del General Diego Domínguez, de profesión comerciante y Teresa Rodríguez. ${ }^{15}$

Este enlace matrimonial reflejó el proceso de reproducción y reestructuración social de la elite tucumana. Por un lado, el casamiento con Águe-

11 Tomas Insúa y Posse — nacido en Torre Gallones, Sant Amet de Sarces (Galicia, España) se casó en Buenos Aires en 1767 con Juana Rosa Collins y Mansilla — descendiente del comerciante inglés John Collins y de María Andreá Mansilla — con quien concibió siete hijos — María Joaquina, María Josefa, Manuel Norberto, Juana Paula, María Cecilia, Mónica Francisca e Ignacio Insúa. Fernández de Burzaco, 1989.

12 Saguier, en línea, (consulta del día 27 de noviembre de 2008), 18.

13 Archivo Histórico de Tucumán (AHT), Sección Protocolos, Serie A, 1792, 173.

14 Las reformas borbónicas generaron la división de la elite en dos facciones. El sector de la elite tradicional descendiente de los viejos troncos coloniales, quienes se manifestaban en contras de estas reformas y el sector pro-borbónico que apoyaba las transformaciones administrativas. Las reformas plantearon una puja por el poder y el espacio en donde se dirimieron estos enfrentamientos fueron el cabildo y la Junta de Temporalidades, encargada esta última de la venta de las tierras que fueran propiedad de la Compañía de Jesús hasta 1767; García Calderón, 2009, 25.

15 Archivo de la Catedral de Tucumán (ACT), Matrimonios III, F. 3. Centro de estudio Genealógicos, 2007. 
da significó para Posse su inserción definitiva al seno de la elite y la posibilidad de acceder al cabildo como funcionario desempeñando diversos cargos. Se transformó en un actor central en la red familiar por su capital económico y sus vínculos comerciales con la elite de Buenos Aires, además del capital simbólico de pertenencia a la migración borbónica. ${ }^{16}$ Por otro lado, evidenció las estrategias familiares utilizadas por familias de la elite tucumana que se vincularon con estos comerciantes peninsulares que emigraron en el contexto de las reformas borbónicas y que se transformarían en la nueva elite comercial del período tardo colonial. ${ }^{17}$

Fruto de su matrimonio con Agueda nacieron siete hijos: José Víctor (26-08-1785/24-05-1852), Simón (1790), Vicente (4-04-1796/09-08-1884), María del Rosario (1794), Luis (10-04-1797), Felipe (30-04-1806/30-071878), Francisco Posse (se desconoce cualquier otro dato al respecto de su persona) quienes ampliaron la red de parentesco vinculándose con otras familias de la elite local. ${ }^{18}$

A partir de su establecimiento definitivo los hermanos Posse estructuraron una red comercial que vinculó a comerciantes del medio local y de Buenos Aires, fortaleciendo estas relaciones mediante las uniones matrimoniales.

\section{Inicios de la red comercial de Manuel Posse, circuitos comerciales de exportación y la incidencia de los vínculos de parentesco en su conformación entre 1790 y 1799}

Antes de adentrarnos específicamente en el estudio de la red de parentesco de Manuel Posse y en el análisis de las exportaciones resulta necesario caracterizar el contexto económico en donde se efectuaron estas actividades.

16 La posición de un individuo en la red está directamente vinculada con la centralidad, la intensidad de los lazos y la dirección dominante, características que se observan en Manuel Posse a partir de su ubicación como un actor económico — sus transacciones y la red comercial que construyó con su hermano- y su posicionamiento político a partir del acceso a cargos en el cabildo. Para comprender más de la evolución de las redes sociales en la historia véase: Amadori y Ponce Leiva, 2008, 20.

17 «...El ascenso de los comerciantes como miembros de la elite se verificó como resultado de su posesión de riquezas provenientes de su actividad mercantil y el acceso a los cargos capitulares [...] esto pudo ser posible merced al entroncamiento que realizaron con familias tradicionales ya encumbradas mediante matrimonios ventajosos. Su ingreso a la ciudad y su reclutamiento como integrantes de la elite complejiza la conformación de la sociedad local...»En Marchionni, 1999, 181.

18 Posse, 1993, 41-48. 
En el siglo XVIII la situación económica de la ciudad de San Miguel de Tucumán era favorable debido a su ubicación como intermediaria en el eje Potosí-Buenos Aires. De acuerdo con Cristina López, la región del Tucumán se caracterizó por su producción ganadera destinada a dos mercados: como ganado en pie que se transportaba hacia las provincias altoperuanas (especialmente a Tarija y Cinti) y como productos derivados (cueros, suelas, grasa, sebo), orientados a los mercados del Litoral. Complementaban la producción local otros bienes como los pellones, el arroz, las maderas, los muebles, las carretas, que se dirigían a la capital del virreinato y zonas aledañas. Desde Tucumán se enviaba el ganado, los pellones y los productos de reexportación (como la yerba y el azúcar) a los mercados del Alto Perú. A cambio de sebo, grasa y quesos se obtenía el metálico y productos manufacturados como los textiles, los sombreros y las mantas. Hacía el Litoral y el puerto de Buenos Aires se destinaban los cueros curtidos, el arroz, las maderas y las carretas. En la ciudad portuaria los comerciantes tucumanos adquirían los «efectos de Castilla», la yerba, el azúcar y las manufacturas que no se producían en la jurisdicción y saldaban las cuentas con plata adquirida en los mercados altoperuano o en la misma capital del Virreinato. ${ }^{19}$

Los comerciantes locales atendían dos mercados. Uno vinculado con la importación de productos — que en el siglo XVIII se incrementó sensiblemente de acuerdo a diversos historiadores - consistente en la importación de efectos de la tierra y efectos de Castilla de bienes que no se producían en la región..$^{20}$

En lo referente al comercio de exportación, se manifestaron diferentes tendencias de acuerdo a las necesidades de los mercados consumidores. ${ }^{21}$ Por este motivo se identificaron los productos locales de exportación entre 1790 y 1799 . Los datos aportados por las fuentes dieron cuenta de que las suelas fueron el principal rubro exportable concentrando el 39\% de los

19 López, 2003, 194.

20 Los principales productos de importación eran los algodones y lienzos del Alto Perú, yerba de Paraguay, Azúcar de Jujuy y Río de Janeiro, aguardientes y vino de la zona de Cuyo, añil de Chile y Perú, entre otros bienes. En López, 1992.

21 Los circuitos comerciales eran tres: Norte: estaba constituido por la jurisdicción de Salta, la jurisdicción de Jujuy y las provincias del Perú que incluían las ciudades de Arequipa, Chichas, Chuquisaca, Cochabamba, Cuzco, la Paz, la Plata, Charcas, Talima, Tayna y Perú. Sur: comenzaba en la ciudad de Santiago del Estero y la de Córdoba e incluía en el tránsito a San Luis y San Juan; la ciudad de Santa Fe y ocasionalmente a Santa Fe, Corrientes y Paraguay. Oeste: formaban parte de este circuito las ciudades de Catamarca (con Andalgalá, Belén, Santa María, Londres), la Rioja, San Juan y Mendoza. Desde ahí ocasionalmente se enviaban productos a Chile y Lima. López, 1992. 
envíos. El segundo producto en cantidad de exportaciones fueron las tablas, hecho relacionado con la riqueza forestal en las sierras al oeste de San Miguel de Tucumán, de donde se extraía la madera para fabricar bateas, sillas y taburetes. A partir de esta información, se indagó cuál fue el circuito comercial que centralizó el volumen de las exportaciones. Se comprobó que el circuito sur concentro el 76\% (751 envíos) de las exportaciones, seguido del norte con el $23 \%$ (226 envíos) y el oeste con $1 \%$ ( 7 envíos). ${ }^{22}$

TABLA N. ${ }^{\circ} 1$

CIRCUITOS DE EXPORTACIÓN DE MANUEL POSSE, 1790/1799

\begin{tabular}{|c|l|c|l|c|}
\hline \multicolumn{5}{|c|}{ Productos enviados por Posse a los distintos circuitos de exportación, 1789-1799 } \\
\hline \multirow{7}{*}{ Circuito sur } & \multicolumn{1}{|c|}{ Producto } & Cantidad & \multicolumn{1}{|c|}{ Destino } & Porcentaje \\
\cline { 2 - 5 } & Suelas & 15 & Buenos Aires & $66 \%$ \\
\cline { 2 - 5 } & Bateas & 4 & Buenos Aires & $18 \%$ \\
\cline { 2 - 5 } & Arroz & 1 & Buenos Aires & $4 \%$ \\
\cline { 2 - 5 } & Quesos & 1 & Buenos Aires & $4 \%$ \\
\cline { 2 - 5 } & Garbanzos & 1 & Buenos Aires & $4 \%$ \\
\cline { 2 - 5 } & Tabla y tablones & 1 & Buenos Aires/Córdoba & $4 \%$ \\
\hline Total & & 23 & & $100 \%$ \\
\hline & Producto & Cantidad & Destino & Porcentaje \\
\hline Circuito norte & Pellones & 8 & Potosí & $100 \%$ \\
\hline Total & & 8 & & $100 \%$ \\
\hline
\end{tabular}

Tabla de elaboración propia. Fuente: AHT, Sección comprobantes de contaduría, Libros de Toma de Razón, período 1789-1799.

Estos datos reafirman la postura de los historiadores locales y nacionales acerca del proceso de atlantización de la economía en el Río de la Plata. ${ }^{23}$ Este redireccionamiento de las exportaciones significó una perdida

22 AHT, Sección comprobantes de contaduría, Libros de Toma de Razón, período 1789-1799.

$23 \ll \ldots$ Es entre 1744 y 1778 que se va a reafirmar definitivamente el papel de Bs. As. como mercado, polo de arrastre y centro de distribución para un vasto conjunto regional. Es decir que la creación del virreinato del Río de la Plata en 1776, con capital en Buenos Aires y todas las medidas que lo acompañaron, fueron más que el origen, la confirmación legal de una realidad que ya empezaba a existir y que por supuesto fue así acentuada al máximo. Desde ese momento los mercaderes de Buenos Aires van a dominar indiscutiblemente sobre toda una vasta área que abarcaba desde el Paraguay hasta Chile, desde Buenos Aires hasta el Alto Perú y aún un poco más allá...», en: Gelman, 1996, 19. 
sustancial de la participación de las exportaciones hacía el Alto Perú, aunque de acuerdo a las fuentes relevadas, todavía mantenía un $23 \%$ del total de los envíos. ${ }^{24}$ En toda esta amplia gama de productos que eran comercializados desde la ciudad de Tucumán, Manuel Posse se especializó en la exportación de algunos productos.

La tabla n. ${ }^{\circ} 1$ ilustra los productos que comercializó Posse hacia los diferentes circuitos en el período 1790-1799. La cuantificación de las exportaciones evidenció además la tendencia de priorizar el circuito sur como escenario comercial teniendo como primer producto exportable, de acuerdo a la cantidad de envíos, a las suelas. En este sentido, se indagó cuáles fueron las motivaciones comerciales que llevaron a Posse a concentrar sus exportaciones hacía Buenos Aires por lo que se identificó a los receptores de los artículos con la finalidad de identificar la lógica económica y si la misma tenía alguna relación con los vínculos familiares.

\section{TABLA N. ${ }^{\circ} 2$}

DESTINATARIOS Y CANTIDADES DE SUELAS ENVIADAS ENTRE 1790 Y 1799

\begin{tabular}{lcc} 
Destinatario & Cantidad & Porcentaje \\
\hline Insúa, Tomas & 2.140 & $43 \%$ \\
Posse, Gerardo Antonio & 1.068 & $22 \%$ \\
Posse, Gerardo y Nadal, Juan & 673 & $14 \%$ \\
Molinuevo, Ángel & 629 & $13 \%$ \\
S/D & 330 & $7 \%$ \\
Canesa, Antonio & 25 & $1 \%$ \\
\hline Total & 4.865 & $100 \%$
\end{tabular}

Fuente: AHT, Sección de Comprobantes de Contaduría y Oficios Varios, Cuadernos de Tomas de Razón en los años 1786-1799

De acuerdo a los datos aportados por la tabla $\mathrm{n} .^{\circ} 2$, el grueso de las exportaciones de suelas hacía Buenos Aires fueron destinadas a Tomás Insúa y Gerardo Posse, hecho que demostró la estructuración de una red comercial entretejida con los vínculos de parentesco, lo que facilitó por una

24 AHT, Sección comprobantes de contaduría, Libros de Toma de Razón, período 1789-1799. 
parte las transacciones económicas y por otra parte, vislumbró un aceitado mecanismo comercial entre los hermanos Posse y su tío. La consolidación económica de Posse se combinó con su inserción en el ámbito político a partir de su designación como Defensor de Menores en 1787, Procurador de la ciudad en 1788, Alcalde de Barrio en 1793 y Diputado de Comercio en $1796 .{ }^{25}$ En este sentido, el proceso que atraviesa Posse caracterizó el período de transición inaugurado por las reformas borbónicas y la paulatina reconfiguración de la elite tucumana a partir de la incorporación de estos nuevos actores sociales.

Asimismo, a partir de los datos aportados por la fuente se analizaron las exportaciones de suelas y el grado de participación de Manuel Posse en el total de las mismas con la finalidad de obtener un panorama aproximado de la situación del peninsular.

\section{TABLA N. ${ }^{\circ} 3$}

EXPORTACIONES DE SUELAS CON DESTINO BUENOS AIRES, 1790-1799

\begin{tabular}{lcc} 
Comerciante & Número de envíos & Cantidad \\
\hline Castro, Pedro Vicente & 5 & 908 \\
Alberdi, Salvador & 9 & 2.950 \\
Monteagudo, Francisco & 11 & 3.841 \\
Rodríguez, Cayetano & 11 & 7.995 \\
Laguna, Miguel & 12 & 2.991 \\
Araóz, Francisco & 13 & 1.837 \\
Posse, Manuel & 15 & 4.865 \\
Terry, Antonio & 15 & 10.354 \\
García, José Gabriel & 17 & 8.321 \\
Ruiz de Huidobro, Julían & 20 & 2.891 \\
Velarde, José & 20 & 6.014 \\
Ponse, Alonso & 29 & 16.101 \\
Reboredo, Manuel & 35 & 9.470 \\
\hline Total & 212 & 78.528
\end{tabular}

Tabla de elaboración propia. Fuente: AHT, Sección Administrativa, comprobantes de Contaduría, Oficios Varios y Libros de Toma de Razón, período 1789-1799.

25 Avellaneda de Ibarreche, Clessi y Corominas, 2005, 370-377. 
La tabla n. 3 refleja que la cantidad de envíos no coincidió siempre con el volumen por unidad de suelas exportadas, hecho que se observó en el caso de Reboredo Manuel, que fue el comerciante que realizó 35 envíos exportando un total de 9.470 unidades (12\%). El comerciante que más suelas exportó fue Ponse, Alonso con 29 envíos con un total de 16.101 unidades (20\%) mientras que Manuel Posse realizó 15 envíos que representaron 4.865 unidades $(6 \%)$ de un total de 78.528 unidades exportadas con destino Buenos Aires. A pesar de que la exportación de suelas no resulta significativa en comparación con otros comerciantes del medio local, da cuenta de una situación de progreso económico sustancial, tomando en cuenta que en 1786 se estableció Manuel Posse en Tucumán. Esto explicó la centralidad de los vínculos familiares como una estrategia para progresar económicamente, hecho que favoreció el aumento paulatino de las exportaciones con el correr de los años.

\section{Comercio de exportación y enlaces matrimoniales de la primera generación de los Posse entre 1800-1810. La consolidación de la red de parentesco}

A comienzos del siglo XIX el vínculo de dominación colonial se encontraba en una profunda crisis, debido a la pérdida progresiva de control por parte de la corona española de sus dominios de ultramar, el franco retroceso del imperio y los continuos enfrentamientos bélicos con el resto de las potencias coloniales, hecho que generó una solicitud constante de metálico para afrontar los gastos de la guerra. La Metrópoli, ante esta situación, aumentó la presión fiscal en los territorios coloniales mediante la implementación de una serie de empréstitos voluntarios. ${ }^{26}$

En el caso del Virreinato de Río de la Plata el cuestionamiento a la autoridad real se acentuó debido a las invasiones inglesas de 1806 y 1807. Estas incursiones fueron rechazadas por los vecinos de Buenos Aires, quienes ante la indeterminación de los funcionarios españoles, emprendieron la reconquista de la ciudad con el auxilio de destacamentos de milicias de las jurisdicciones próximas.

Una de las primeras preocupaciones se vinculó con indagar si la tendencia económica que manifestó Manuel Posse hacía Buenos Aires se

26 Los empréstitos fueron de dos características, voluntarios y forzosos. En cuanto los primeros, los vecinos contribuían con los montos que creían convenientes, mientras que en los segundos por los general se prorrateaba de acuerdo al criterio impuesto por el Diputado de Comercio. 
mantuvo constante en la primera décadas del siglo XIX. En este período, el circuito sur concentró el $82 \%$ de las exportaciones aunque el total de envíos disminuyó de 751 a 524 en referencia al período 1790-1799. A pesar de este descenso, la tendencia se mantuvo constante en cuanto al crecimiento de la participación de la ciudad de Buenos Aires como polo de atracción económica. El circuito norte disminuyó de un $23 \%$ a un $18 \%$ para el período, lo que indicó una disminución en el total de las exportaciones tucumanas con respecto al decenio de 1790-1799. ${ }^{27}$

Asimismo, el interés en el estudio de este primer decenio se vinculó con comprobar si Manuel Posse mantuvo el flujo de envíos hacía la ciudad de Buenos Aires o si la villa de Potosí captó la atención económica del peninsular.

\section{TABLA N. ${ }^{\circ} 4$}

CIRCUITOS DE EXPORTACIÓN DE POSSE ENTRE 1800-1809

\begin{tabular}{|c|l|c|l|c|}
\hline \multicolumn{5}{|c|}{ Productos enviados por Posse a los distintos circuitos entre 1800 y 1809} \\
\hline \multirow{7}{*}{ Circuito sur } & \multicolumn{1}{|c|}{ Producto } & Cantidad & \multicolumn{1}{|c|}{ Destino } & Porcentaje \\
\hline & Suelas & 35 & Buenos Aires & $72 \%$ \\
\cline { 2 - 5 } & Bateas & 5 & Buenos Aires & $10 \%$ \\
\cline { 2 - 5 } & Arroz & 3 & Buenos Aires & $6 \%$ \\
\cline { 2 - 5 } & Lanas de guanaco & 1 & Buenos Aires & $2 \%$ \\
\cline { 2 - 5 } & Sombreros & 1 & Buenos Aires & $2 \%$ \\
\cline { 2 - 5 } & Quesos & 1 & Buenos Aires & $2 \%$ \\
\cline { 2 - 5 } & Garbanzos & 1 & Buenos Aires & $2 \%$ \\
\cline { 2 - 5 } & Sillas y taburetes & 1 & Buenos Aires & $2 \%$ \\
\cline { 2 - 5 } & Tabla y tablones & 1 & Córdoba & $2 \%$ \\
\hline \multirow{7}{*}{ Total } & & 23 & & $100 \%$ \\
\hline \multirow{3}{*}{ Circuito norte } & Cantidad & & Destino & Porcentaje \\
\hline \multirow{2}{*}{ Total } & Producto & 11 & Potosí & $92 \%$ \\
\cline { 2 - 5 } & Sillas y taburetes & 1 & Potosí & $8 \%$ \\
\hline
\end{tabular}

Tabla de elaboración propia. Fuente: AHT, Sección Administrativa, comprobantes de Contaduría, Oficios Varios y Libros de Toma de Razón, período 1789-1799.

27 AHT, Sección comprobantes de contaduría, Libros de Toma de Razón, período 1800-1809 
De acuerdo con los datos aportados por la tabla $\mathrm{n}^{\circ}$, en el período 1800-1809 Manuel Posse amplió la gama de productos exportados hacía Buenos Aires incorporándose los sombreros, las sillas y taburetes y las lanas de guanaco, hecho que resultó significativo debido a que si bien los envíos no son fueron importantes, en cuanto a la cantidad, demostraron una tendencia a diversificar las exportaciones y captar nuevos mercados. Asimismo, Manuel incrementó sustancialmente los envíos de suelas hacía Buenos marcando una diferencia con respecto al resto de los productos que exportó, pero además implicó una especialización en cuanto a este artículo específico.

A partir de este panorama que brindaron las fuentes, se analizó quienes fueron los receptores de este artículo en Buenos Aires y se comprobó que el único destinatario de los 29 envíos (11.020 suelas) fue Gerardo Posse. ${ }^{28}$ Esto marcó una diferencia importante con el período 1789-1799, desde dos perspectivas. Por un lado, el principal receptor de este producto dejó de ser Tomás Insúa tomando ese lugar Gerardo Posse y por otro lado, la totalidad de los envíos quedaron en el entorno de la red familiar, cosa que no ocurrió en el período anterior en donde participaron comerciantes que eran ajenos a ella. ${ }^{29}$ Siguiendo la lógica de análisis del período anterior, se indagó cuáles fueron los comerciantes que exportaron suelas con destino Buenos Aires con la finalidad de observar la situación de Posse en este nuevo período (tabla n. ${ }^{\circ}$ ).

En el período que reflejó la tabla n. ${ }^{\circ}$ 5, Manuel Posse realizó 35 envíos exportando 12.530 unidades, lo que representó el $23 \%$ un total de 57.563 unidades enviadas a la ciudad de Buenos Aires. Esto lo transformó en el comerciante con mayor participación en este rubro. El segundo comerciante fue Manuel Reboredo que efectuó 23 envíos, exportando 11.143 unidades que significaron el $19 \%$ del total.

La primera década el siglo XIX marcó también el inició de las uniones matrimoniales de los hijos del peninsular, quienes capitalizaron las relaciones previamente efectuadas por su padre con distintas familias de la elite tucumana. El primero en casarse fue José Víctor Posse, que contrajo matrimonio con Tomasa Pereira y Araóz. Era hija del prominente español

28 AHT, Sección de Comprobantes de Contaduría y Oficios Varios, Cuadernos de Tomas de Razón en los años 1800-1809.

29 Esta estrategia económica manifestó a la centralidad de los hermanos Posse en el vinculo comercial evitando los intermediarios y concentrando las exportaciones hacia Buenos Aires por sobre cualquier otro circuito. 
Manuel Antonio Pereira, quien fuera designado Diputado de Comercio en Tucumán en 1788, Alcalde de la Santa Hermandad en 1796 y Teniente Tesorero en $1801^{30}$ y de Magdalena Aranguren Aráoz emparentada con Bernabé Araóz, quien fuera elegido como el primer gobernador propietario de la provincia de Tucumán entre 1814-1817 y presidente fundador de la República del Tucumán entre 1820-1821. ${ }^{31}$ La consumación de matrimonio resultó clave debido que entrecruzó a dos familias de orígenes diversos, los Posse, provenientes de la migración borbónica, y los clanes familiares de los Pereira y los Araóz, quienes descendían de dos antiguos linajes tucumanos vinculados a la vida comercial y política de la ciudad e integrantes de la elite tradicional. ${ }^{32}$

$$
\text { TABLA N. }{ }^{\circ} 5
$$

EXPORTACIONES DE SUELAS CON DESTINO BUENOS AIRES, 1800-1809

\begin{tabular}{lcc} 
Comerciante & Número de Envíos & Cantidad \\
\hline Araóz, Cayetano & 7 & 800 \\
Araóz, Gregorio & 7 & 1.196 \\
Monteagudo, Francisco & 10 & 2.246 \\
Ponse, Alonso & 10 & 3.318 \\
Zavaleta, Clemente & 11 & 2.309 \\
Pondal, Roque & 12 & 2.674 \\
Araóz, Bernabé & 12 & 3.095 \\
Garmendia, José Ignacio & 12 & 2.939 \\
Terry, Antonio & 14 & 8.253 \\
Rodríguez, Cayetano & 21 & 7.060 \\
Reboredo, Manuel & 23 & 11.143 \\
Posse, Manuel & 35 & 12.530 \\
\hline Total & 139 & 57.563
\end{tabular}

Tabla de elaboración propia. Fuente: AHT, Sección Administrativa, comprobantes de Contaduría, Oficios Varios y Libros de Toma de Razón, período 1800-1809

30 Avellaneda de Ibarreche, Clessi y Corominas, 2005, $384-406$.

31 Aparte de ser designado Diputado de Comercio en varias oportunidades, Manuel Pereira se desempeñó como Teniente Tesorero en 1801. Avellaneda de Ibarreche, Clessi y Corominas, 2005, $384-406$.

32 Bernabé Araóz era hijo de Juan Araóz y Josefa Córdoba La familia Araóz era propietaria de numerosas extensiones de tierras en el departamento Monteros ubicado al sur de la capital de Tucumán. Groussac los describió como señores feudales en esas comarcas, en Groussac, 1981, 182. 
La única hija de Manuel Posse, María del Rosario, se casó en 1806 con Roque Pondal y Blanco. ${ }^{33}$ El peninsular nació en Camariñas en 1783 y se encuentra radicado en la ciudad de San Miguel de Tucumán en los primeros años del siglo XIX. Emigró hacia Tucumán por los contactos existentes entre parientes de la zona de Camariñas, lo que llevó al peninsular a emigrar a la zona del Río de la Plata. En el censo de 1812 figura con la edad de 28 y en el padrón de electores de 1818 figura con residencia en el Tercer Cuartel de la ciudad - en la zona sur- como europeo endonado de 34 años, casado y de profesión comerciante. ${ }^{34}$ Pondal se desempeñó como Procurador General (1810), Regidor Decano (1821), Alcalde Ordinario de Segundo voto (1822), Juez de $1^{\circ}$ Nominación en lo Civil (1826) y Diputado de la Sala de Representantes (1829-1831). ${ }^{35}$ Este matrimonio permitió, por un lado, la inserción social de Roque Pondal en el contexto tucumano y por otro lado, resultó una prueba de la fortaleza de los vínculos parentales transatlánticos existentes entre connacionales que emigraron de las mismas regiones de la península ibérica, lo que conllevó a un fortalecimiento de la red familiar y la incorporación de un nuevo actor comercial con un estrecho vínculo de parentesco a la red comercial. ${ }^{36}$

Tanto Manuel Antonio Pereira, padre de Tomasa, como Roque Pondal mantenían un fluido contacto comercial con Gerardo Posse, quien era el destinatario de los productos exportados por ambos comerciantes a Buenos Aires. ${ }^{37}$ Estas uniones matrimoniales fortalecieron la red comercial de los Posse al incorporar dos prominentes comerciantes del medio local.

\section{Comercio de exportación y uniones matrimoniales de los Posse entre 1810-1819}

El proceso revolucionario iniciado en 1810 generó una movilización de recursos destinados al mantenimiento del ejército revolucionario que

33 En Terán, 2004, 63.

34 AHT, Sección Administrativa, Censo de 1812, 203. Zelarayán, 2003, Tucumán.

35 Terán, 2004, 64.

36 En todo caso, de acuerdo a las fuentes no sólo el vínculo entre connacionales llevó a Pondal a emigrar hacía Tucumán, sino el parentesco de segundo grado a través del apellido Blanco debido a que las madres de ambos peninsulares eran de este apellido.

37 Manuel Antonio Pereira efectuó 13 envíos hacía Buenos Aires de los cuales 8 fueron para Posse. En cambio, todas las exportaciones de Pondal se orientaron a través de la red comercial de la familia Posse. En AHT, Sección de Comprobantes de Contaduría y Oficios Varios, Cuadernos de Tomas de Razón en los años 1800-1809. 
afectó directamente a los comerciantes tucumanos desde dos perspectivas. Por una parte, la revolución significó un recorte sustancial del tráfico comercial con las provincias del Alto Perú, hecho que orientó en forma definitiva las exportaciones tucumanas hacía Buenos Aires. Por otra parte, el sostenimiento de la guerra generó la necesidad de metálico para mantener los ejércitos motivo por el cual, las autoridades del gobierno central recurrieron a una serie de empréstitos forzosos que afectaron directamente a los comerciantes debido a que poseían una mayor disponibilidad de circulante.

$\mathrm{Al}$ respecto de las transacciones comerciales de Manuel Posse y de sus hijos sólo se obtuvo información parcial debido a que la prospección de las guías de comercio para la década revolucionaria resultó dificultosa por la falta de indexación de estas fuentes. ${ }^{38} \mathrm{Sin}$ embargo, los datos relevados permitieron una aproximación a la naturaleza de las transacciones económicas de Posse y de sus hijos quienes comenzaron sus actividades comerciales en esta década.

En los primeros años de la revolución, los circuitos comerciales vinculados con el Alto Perú se desarticularon paulatinamente. Esto alteró la relación entre los mercados proveedores de plata, hecho que generó una marcada iliquidez, recesión y aumentó de precios que afectó directamente a los comerciantes tucumanos por la falta de circulante.

Asimismo, la guerra fue otro elemento que afectó directamente a la ciudad de San Miguel de Tucumán, escenario de la batalla de 1812, en donde el general Belgrano frenó el avance del ejército realista que luego del triunfo de Huaqui (1811) en el Alto Perú marchó sobre el territorio de las provincias unidas del Río de la Plata, poniendo en peligro la marcha de la revolución. A partir del éxito militar en Tucumán, Belgrano volvió a derrotar a los realistas en la batalla de Salta y continúo sus operaciones militares hacia el Alto Perú, aunque una parte del ejército patriota permaneció acantonada en la ciudad hasta 1819 como defensa de la retaguardia. ${ }^{39}$ Esta situación generó una necesidad creciente de recursos por parte de las autoridades revolucionarias que implementaron contribuciones forzosas que afectaron sobre todo - aunque no exclusivamente- a los comerciantes.

38 Para el período revolucionario, sólo se llego a relevar las guías de exportación entre los años 1810-1813. Por este motivo, se recurrió a otras fuentes para complementar la información acerca de la red comercial de la familia Posse.

39 Davio, 2009. 
A pesar de esta situación de inestabilidad provocada por el proceso revolucionario, Manuel Posse y sus hijos efectuaron algunos envíos, 8 de bateas y 11 de suelas, hacia Buenos Aires que tuvieron como destinatarios a Gerardo Posse, como se observó en la tabla n. ${ }^{\circ} 6$.

\section{TABLA N. ${ }^{\circ} 6$}

PRODUCTOS Y CANTIDAD DE ENVÍOS A GERARDO POSSE ENTRE 1810 Y 1813

\begin{tabular}{lcc} 
Comerciantes & Envíos de Bateas & Envíos de Suelas \\
\hline Posse, Manuel & S/D & 3 \\
Posse, Luis & 1 & 1 \\
Posse, Francisco & 3 & 1 \\
Posse, Simón & 3 & 5 \\
Pondal, Roque & 1 & 1 \\
\hline Total & 8 & 11
\end{tabular}

Fuente: AHT, Sección de Comprobantes de Contaduría y Oficios Varios, 1810-1813

A partir de esta información, se observó que Simón Posse concentró la mayor cantidad de transacciones comerciales efectuando 8 envíos seguido por su hermano Francisco con 4 y su padre Manuel con 3. En todo caso, más allá de los datos cuantitativos aportados por esta tabla es posible percibir dos cuestiones. Por un lado, los hijos de Posse en los orígenes de sus transacciones comerciales concentraron su atención en la exportación de los productos (suelas y bateas) a partir de los cuales su padre consolidó su capital mercantil y, por otro lado, aprovecharon las rutas comerciales, como ocurrió en el caso de Roque Pondal, quien exportó pellones a la villa de Potosí a los mismos consignatarios de su suegro, Manuel Posse. ${ }^{40}$

La retracción de este último se vinculó sobre todo con que el recambio generacional que coincidió con el nuevo contexto económico y político. De acuerdo con Cristina López, algunas familias tucumanas dedicadas a las actividades comerciales se vieron en serios problemas de continuidad para mantener la estructura mercantil debido a que carecían de hijos varones para prolongar las mismas, caso contrario de Manuel Posse que inició

40 Roque Pondal en la década revolucionario efectuó 5 envíos de pellones a la Villa de Potosí que tuvieron como destinatario Castelo y Casal Juan, quien Manuel Posse realizó 22 envíos entre 1793 y 1811. En AHT, Sección, CC y OV, período 1793-1811. 
a sus hijos, quienes con algunas dificultades, se adaptaron a las nuevas estrategias mercantiles que impuso la década revolucionaria. ${ }^{41}$

A pesar de esta coyuntura adversa, los comerciantes peninsulares de la plaza local detentaban el mayor giro comercial, aunque esta situación corrió de manera desfavorable debido a que fue el sector más exigido con las cargas impuestas para el mantenimiento del ejército. ${ }^{42}$ Las autoridades del gobierno central impusieron 9 empréstitos en la década revolucionaria con cargo a devolución por la caja de Buenos Aires. ${ }^{43}$ En 1813 las autoridades locales realizaron un censo en el sector de comerciantes para establecer el capital existente en la ciudad. ${ }^{44}$ Esta medida tenía la finalidad de establecer una contribución para el sostenimiento del ejército y el monto de la misma varió de acuerdo al capital que poseía cada individuo. En esta oportunidad, Manuel Posse era el comerciante más acaudalado de la ciudad con un capital de giro comercial estimado en $\$ 60.000$, de acuerdo a lo declarado, por lo que aportó $\$ 1.125$ que fue el monto más elevado. ${ }^{45} \mathrm{El}$ único hijo que aparece censado fue José Víctor con una fortuna estimada en $\$ 7.000$ motivo por el cual tributo $\$ 475$. En este caso específico se evidenció que este integrante del clan Posse se situó entre los comerciantes de menor patrimonio en la ciudad. Sin embargo, al contrastar esta información con el capital que poseía al momento de su muerte (\$35.091 en 1852) se deduce que era un comerciante en franco ascenso en el contexto local. ${ }^{46}$ En la misma situación se encontraba Roque Pondal, quien contaba con un capital de $\$ 5.000$ en 1813 .

En todo caso, tanto Manuel Posse como sus hijos afrontaron a lo largo de la década revolucionaria nuevos empréstitos, transformándose el padre, por su origen español peninsular, en quien recayó el peso de las contribuciones solicitadas por las autoridades del gobierno central (tabla n. ${ }^{\circ}$ ).

41 López, 2009, 119.

42 De acuerdo con Leoni Pinto, el pedido recurrente de empréstitos sumado a la falta de garantías de la devolución del monetario contribuido generó cierta resistencia de los contribuyentes extraordinarios. El eje de los reclamos se centró en la paupérrima situación económica por la que atravesaban en el ámbito local. En Leoni Pinto, 2007, 45.

43 Bolsi, 2010.

44 El capital existente en la ciudad era de $\$ 320.000$, de los cuales $\$ 185.000$ pertenecían al sector de comerciantes peninsular, $\$ 89.000$ de comerciantes tucumanos y $\$ 34.000$ de otros individuos de los cuales no se consignó dato alguno. AHT, Sección Administrativa, 1813, 482.

45 Los 60.000 pesos no eran la cantidad de monetario que poseía Posse en su poder al momento del censo, sino una estimación de todos los recursos materiales de los que era propietarios, entre ellos, propiedades, existencias en su almacén, dinero en efectivo, etc.

46 Archivo de la Provincia (AP), Sección Judicial Civil, Serie A, Caja 91, 1852, 1-30. 
TABLA N. ${ }^{\circ} 7$

DINERO APORTADO POR LA FAMILIA POSSE EN LOS EMPRÉSTITOS DE LA DÉCADA DE $1810^{47}$

\begin{tabular}{lccccccc}
$\begin{array}{l}\text { Integrantes de } \\
\text { la familia }\end{array}$ & Patria & Ocupación & 1813 & 1815 & 1816 & 1819 & Totales \\
\hline Posse, Manuel & Español europeo & Comerciante & $\$ 1.125$ & S/D & Exceptuado & $\$ 1.890$ & $\$ 3.165$ \\
Posse, José Víctor & Tucumano & Comerciante & $\$ 434$ & $\$ 350$ & $\$ 130$ & $\$ 580$ & $\$ 1.494$ \\
Posse, Simon & Tucumano & Comerciante & & $\$ 300$ & $\$ 70$ & $\$ 139$ & $\$ 509$ \\
Posse, Vicente & Tucumano & Comerciante & $\$ 100$ & $\$ 75$ & $\$ 140$ & $\$ 315$ \\
Posse, Francisco & Tucumano & Comerciante & $\$ 200$ & $\$ 30$ & & $\$ 230$ \\
Posse, Luis & Tucumano & Dependiente & $\$ 100$ & $\$ 65$ & $\$ 279$ & $\$ 444$
\end{tabular}

Tabla de elaboración propia. Fuente: AHT, Sección Administrativa, Años 1813, 1815, 1816 y 1819.

Las continuas exacciones por parte del gobierno revolucionario no fueron el único problema que Posse enfrentó en este período debido a que los empréstitos eran ejecutados con cargo a devolución por la Caja de Buenos Aires. Estas restituciones del monetario entregado no eran cumplimentadas por las autoridades, motivo por el cual Manuel solicitó la devolución de un empréstito en 1815, lo que generó la reacción de las autoridades tucumanas. ${ }^{48}$

El pedido de Posse de la restitución del empréstito se interpretó de dos maneras. Por un lado, se manifestó como la intención del peninsular por recuperar el dinero prestado ante la demora por parte del gobierno central de la devolución de los mismos. Por otro lado, fue una forma de mostrar la inconformidad ante el proceso de revolución y guerra que se vivía, hecho que alteró la situación privilegiada de los comerciantes peninsulares en el contexto tucumano. No fue posible a partir de este pedido denominar a Posse como «realista» debido a la delicada situación en la que se encontraban los peninsulares. Leoni Pinto con respecto a esto afirma: «... los posibles enemigos del sistema debían mostrar una actitud muy cauta [...] Más aún debieron dar muestras de ferviente patriotismo...». ${ }^{49}$

47 En esta tabla no se realizó una distinción de los distintos empréstitos sino del total aportado en cada año.

48 «...Posse debe ser castigado para servir de ejemplo a otros que se valieron de iguales y maliciosas acechanzas, por tratar de aniquilar y detener sin suceso los progresos de sus benefactores [...] Posse pide el reintegro de los 3.000 pesos cuando no le hacen falta y cuando esta capital se halla sumergida en un abismo de penas porque a pesar de sus esfuerzos patrióticos, acaso sin iguales, no puede socorrer a los valientes inválidos, viudas y ausentes de los que sostienen el campo de Marte....» Leoni Pinto, 2008, 43

49 Leoni Pinto, 2008, 37. 
Si bien, la situación «política» de Posse se vio comprometida por estas acusaciones, estos hechos no perjudicaron a sus hijos, quienes desde los inicios del proceso revolucionario realizaron constantes demostraciones de patriotismo integrando cuerpos de ejército y contribuyendo en todas las ocasiones que se les solicitó. ${ }^{50}$

El contexto revolucionario no alteró las estrategias matrimoniales debido a que los hijos de Posse continuaron ampliando los vínculos con otras familias de la elite local.

\author{
Gráfico n. ${ }^{\circ} 1$ \\ UNIONES MATRIMONIALES DE LA PRIMERA GENERACIÓN
}

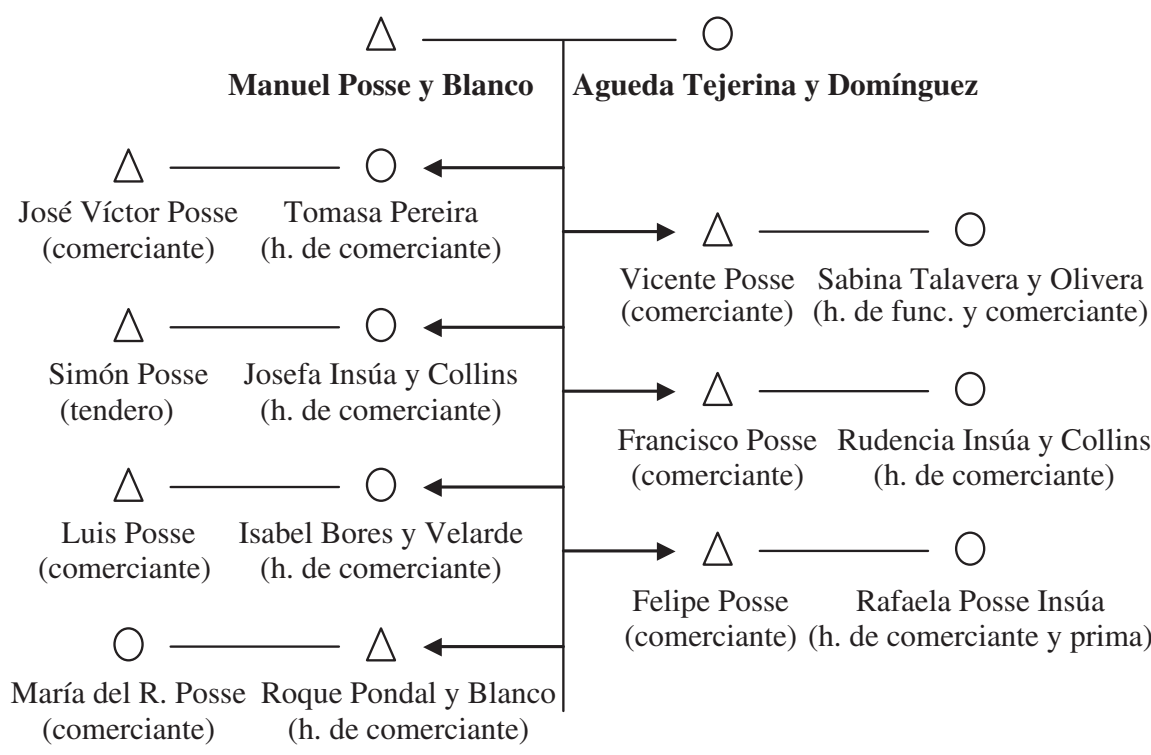

Gráfico de elaboración propia. Fuente: Boletín genealógico de Tucumán, 2005. http://gw5. geneanet.org/sealcari?lang=es;pz=selva+alicia; $\mathrm{nz}=$ casaballe+rios; $\mathrm{ocz}=0 ; \mathrm{p}=\mathrm{d} .+$ gerardo+antonio; $\mathrm{n}=$ posse+y+blanco. Fecha de consulta: 16 de febrero de 2006.

50 En el ejército participó Simón Posse, quien se alistó en el Regimiento de Caballería y un año después lo hizo Luis que integró la Primera Compañía de Comerciantes. AHT, Sección Administrativa, 1810, 33-44, 1811, 13-14. 
En 1810 Simón contrajo matrimonio con su prima porteña Josefa Insúa y Collins, hija del comerciante Tomás Insúa (tío de Manuel) a quien exportaba suelas desde Tucumán. ${ }^{51}$ El enlace de Simón fortaleció los lazos comerciales y parentales con sus familiares porteños. Su hermano Francisco reafirmó nuevamente este vínculo al casarse en la ciudad de Buenos Aires con su prima Rudencia Insúa y García, prima de la esposa de Simón..$^{52}$ Estos matrimonios reflejan una etapa de fortalecimiento de los vínculos de parentesco con familiares directos.

José Víctor se casó en 1815 con Sabina Talavera y Olivera en la iglesia matriz de la ciudad de Santiago del Estero. ${ }^{53}$ Sabina era hija de José de Talavera, destacado comerciante y militar de extensa carrera que participó en la reconquista de Buenos Aires de 1806. Llegó al grado de coronel y fue hermano de la prestigiosa Tercera Orden de la Penitencia en Santiago del Estero. ${ }^{54}$ Este enlace resulto una estrategia implementada por ambas familias para iniciar el vínculo comercial, hecho que posibilitó a Vicente relacionarse con otras familias de Santiago, por medio de su suegro, con las que efectivizó nuevos vínculos mercantiles.

Luis Posse, a diferencia de sus otros hermanos, contrajo matrimonio con Isabel Bores, hija legítima del español Francisco Bores y Carmen Velarde, residentes en la ciudad de San Miguel de Tucumán. ${ }^{55}$ Bores era uno de los comerciantes más destacados de la ciudad con un capital de giro comercial en 1813 de $\$ 16.000 .{ }^{56}$ Exportaba suelas, cueros, arroz, quesos, entre tantos otros productos a Buenos Aires, siendo uno de los que aportó mayores avances a la producción tabacalera en Tucumán. Su mujer era hermana de José Velarde, uno de los comerciantes más prominentes de San Miguel en 1813, con una fortuna calculada en 35.000 pesos. ${ }^{57}$

Felipe Posse, el menor de los hijos de Manuel, fue el primero de los descendientes que contrajo matrimonio con una sobrina carnal, Rafaela Posse Insúa (hija de Simón). ${ }^{58}$ Rafaela quedó huérfana a corta edad, quedándose al cuidado de su tío José Víctor. El casamiento de Felipe con su

51 Posse, 1996, 170.

52 Posse, 1996, 175.

53 Archivo de la Catedral de Santiago del Estero (ACS), 1815, matrimonios I, sección matrimonios entre españoles, $2 .^{\circ}$ parte, 3 .

54 Centro de Estudios Genealógicos, 2003, 7.

55 Posse, 1996, 175

56 AHT, Sección Administrativa, 1813, 351.

57 AHT, 1813. 351.

58 Posse, 1996, 47. 
sobrinase interpretó como una estrategia para resguardar el patrimonio familiar. Este enlace fue el primero en el entorno intrafamiliar y a partir del mismo esta práctica fue recurrente con el transcurso de las generaciones.

Las uniones matrimoniales de los hijos de Posse demostraron la capacidad por entretejer intereses mercantiles con estrategias de reproducción social mediante las cuales transitaron - no sin dificultades- la década revolucionaria y posteriormente se consolidaron en las décadas posteriores.

\section{Conclusiones}

A fines del siglo XVIII las reformas borbónicas propiciaron la migración de numerosos comerciantes peninsulares, en su mayoría de origen gallego, quienes a partir de la aprobación del Tratado de Libre Comercio buscaron consolidar nuevas rutas para el tráfico mercantil entre la Metrópoli y las colonias. En el ámbito tucumano este proceso fue estudiado por los historiadores locales que analizaron el período tardo colonial, transformándose el estudio de los hermanos Posse en otra prueba empírica de la inserción social de estos peninsulares, de su rápida adaptación al medio y la manera en que aprovecharon su capital simbólico como una herramienta para generar nuevos vínculos con la elite tucumana.

Un elemento ineludible relacionado con la reconstrucción de las redes familiares de los Posse se vinculó con el estudio de las pautas migratorias de estos actores sociales y de su relación con redes de parentesco más amplias, de carácter transoceánico; fenómeno analizado en el caso del Río de la Plata para el período colonial por la historiografía rioplatense. Esta reconstrucción de las redes realizadas por diferentes autores (Socolow, Brading, entre otros), sirvió como elemento para reflexionar en este caso específico. A partir de la información obtenida de las fuentes se advirtió que el proceso migratorio iniciado por Gerardo y Manuel Posse hacía el Río de la Plata no fue casual debido a que Tomás Insúa y Collins, tío de ambos, residía en la ciudad de Buenos Aires. Este vínculo previo fue determinante al momento de decidir hacia que región emigrar del territorio colonial.

Las uniones matrimoniales efectuadas por los hermanos marcaron diferentes realidades. Por un lado, el casamiento de Gerardo con su prima María Insúa y Collins significó su inserción en el contexto comercial de la plaza porteña y la reafirmación de los lazos de parentesco entre los Posse 
y los Insúa; estrategia que permitió la incorporación de Gerardo a las actividades comerciales efectuadas por Tomás Insúa y la posibilidad de incrementar paulatinamente contactos comerciales y capital económico. A partir de este crecimiento Gerardo se transformó en el principal destinatario de las exportaciones de Manuel y de otros comerciantes tucumanos, reemplazando a su tío, quien en un primer momento ocupó la centralidad de esta red comercial.

Por otro lado, la unión matrimonial de Manuel Posse con Agueda Tejerina y Domínguez significó la incorporación del peninsular a la elite tucumana, la posibilidad de aprovechar los contactos comerciales del tío de su esposa, Diego Domínguez, quien era propietario de una pulpería en la ciudad y de vincularse con el mercado Alto peruano que mantenía un flujo significativo de importaciones desde Tucumán, a pesar del proceso de atlantización de la economía en el Río de la Plata.

Las uniones matrimoniales de los hijos de Manuel Posse respondieron a la misma lógica, debido que algunas reafirmaron los lazos de parentesco con los Insúa, propiciaron la concentración alrededor del núcleo familiar de otras familias relacionadas con las actividades comerciales como los Pereira y Borges, hecho que fue capitalizado en la transición del período tardo colonial y el proceso de revolución e independencia. En este sentido, la figura central de la red en el ámbito local fue Manuel Posse debido a que propició las uniones matrimoniales de sus hijos, les prestó el capital para la instalación de sus pulperías y los incorporó al aceitado circuito comercial que estructuró con su hermano Gerardo Posse.

En cuanto al tema de las exportaciones tucumanas, se ha intentado a partir de la elaboración de diferentes gráficos ilustrar la naturaleza de los intercambios comerciales entre Tucumán y otras regiones; la tendencia hacía el circuito sur y sobre todo aproximarnos a la realidad comercial de Manuel Posse.

El estudio de las exportaciones en el caso de Manuel resultó clave con la finalidad de indagar en la evolución de la participación del peninsular en un rubro específico como las suelas. Si bien sólo se cuantificaron los envíos desde dos parámetros - cantidad de envíos y unidades- esto reflejó el crecimiento de Manuel, al transformarse en el período 1800-1809 en el principal exportador de suelas de Tucumán. Asimismo, el estudio de este producto específico sirvió como evidencia de cómo se estructuró la red comercial de los hermanos Posse, transformándose Gerardo en el receptor de los productos enviado por Manuel. 
Los datos relevados a las exportaciones en la década revolucionaria resultaron una muestra sugerente en cuanto a la incorporación efectiva de los hijos de Manuel Posse a la red comercial. Sin embargo, el proceso revolucionario generó la necesidad recurrente de recursos para mantener al ejército del Norte, peso que recayó en los comerciantes peninsulares de la plaza tucumana, entre ellos Manuel Posse. Los empréstitos solicitados permitieron a la vez deducir la situación económica en la que se encontraban los hijos de Posse porque a partir de las contribuciones, que se prorrateaban de acuerdo a la fortuna, se evidenció que los descendientes del peninsular todavía se situaban en un momento de consolidación de su capital económico.

Recibido el 09 de febrero de 2012

Aceptado el 17 de septiembre de 2012

\section{Bibliografía}

Aljovín, Cristóbal y Jacobsen, Nils (eds.): Cultura política en los Andes, 17501950, Lima, UNMSM/IFEA, 2007.

Annino, Antonio: «La ciudadanía ruralizada. Una herencia de la crisis imperial», Jornada Internacional de Debate «Los historiadores y la conmemoración de los Bicentenarios», Rosario, 2006.

Avellaneda de Ibarreche, Celia, Clessi, María del Carmen y Corominas, Jorge: «Autoridades del Cabildo, Justicia y Regimiento - tercera parte (17791824)», en Centro Genealógicos de Tucumán, Boletín, 5, Tucumán, 2005, 370, 371 у 377 .

Bascary, Ana María: «Poder y familia en San Miguel de Tucumán a fines del período colonial. El caso de los Villafañe», en Actas del IV Encuentro de Latinoamericanistas Españoles, Salamanca, 1995, 2075-2096.

Bascary, Ana María: Familia y vida cotidiana. Tucumán a fines de la colonia, Tucumán, Facultad de Filosofía y Letras, UNT - UPO, 1999.

Bertrand, Michel: «De la familia a la red de sociabilidad», Revista de Sociología, México, 1, 2, abril-junio, 1999, 107-135.

Bolsi, Francisco: «Orígenes, estrategias familiares y reproducción social de la elite tucumana. Una aproximación a partir del análisis comparado de las familias Posse y Nougués, 1830-1930», Revista Historia de América, México, 139, enero-diciembre, 2008, 135-168.

Bolsi, Francisco: «Familias de la elite, revolución y guerra. Una aproximación a partir del clan Posse en Tucumán, 1810-1830», Revista Secuencia, México, enero-abril, 75, 2010, 39-59. 
Centro de Estudios Genealógicos de Tucumán, Boletín 3, Tucumán, 2003, 7.

Centro de Estudios Genealógicos de Tucumán Boletín 5, Tucumán, 2007.

Chust, Manuel y Serrano, Antonio (eds.): Debates sobre las independencias iberoamericanas, Madrid/Francfurt, Iberoamericana/Vervuert, 2007.

Crespo Pozo, Santiago: Blasones y linajes de Galicia, Santiago de Compostela, Ed. de los bibliófilos gallegos, 1958-1985, 5 vols.

Davio, Marisa: «El proceso de militarización durante la revolución. Tucumán, 1812-1819», en López, Cristina (comp.), Del Antiguo Régimen a la Revolución: Identidades sociales, representación y poder en Tucumán y la región (1750-1850), Rosario, Prohistoria, 2009, 83-102.

Davio, Marisa: «El proceso de militarización en Tucumán: experiencias e identidades de los sectores populares», en Historia y Memoria, 2, Tunja, Boyaca, 2011, 93-124.

Di Meglio, Gabriel: ;Viva el bajo pueblo! La plebe urbana de Buenos Aires y la política entre la Revolución de Mayo y el rusismo (1810-1829), Buenos Aires, Prometeo ediciones, 2005.

Fernández de Burzaco, Hugo: Apuntes biogenealógicos para un padrón de habitantes del Río de la Plata, Buenos Aires, Instituto Argentino de Estudios Genealógicos, 1989, 6 vols.

Garavaglia, Juan Carlos: «Ejército y milicia: los campesinos bonaerenses y el peso de las exigencias militares, 1810-1860», Anuario IHES, Tandil, 2003, 153-187.

Gelman, Jorge: De mercanchifle a gran comerciante. Los caminos del ascenso en el Río de la Plata colonial, Sevilla, Universidad Internacional de Andalucía, 1996.

Gilbert y Nugent (eds.): Aspectos cotidianos de la formación del estado. La revolución y la negociación del mando en el México moderno, México, Ed. Era, 2002.

Goldman, Noemí: «Crisis imperial, revolución y guerra (1806-1820)», en Goldman, Noemí (directora de tomo): Nueva Historia Argentina. Revolución, República, Confederación (1806-1852), Buenos Aires, Sudamericana, 3, 1999, 21-69.

Groussac, Paul: Ensayo histórico sobre Tucumán, Tucumán, Ediciones Banco Comercial del Norte, 1981.

Herrero, Fabián, (Comp.): Revolución. Política e ideas en el Río de la Plata durante la década de 1810, Buenos Aires, Ediciones Cooperativas, 2004.

Herrero, Fabián: Movimientos de Pueblo. La política en Buenos Aires luego en 1810, Buenos Aires, Ediciones Cooperativas, 2007.

Iramain, Pablo: «El proceso de independencia a través de las familias principales. Tucumán entre 1810-1820», en: García de Saltor, Irene y López, Cristina (comp.), Representaciones, sociedad y poder. Tucumán en la primera mitad del siglo XIX, Tucumán, Facultad de Filosofía y Letras, UNT, 2005, 85-132. 
Leoni Pinto, Ramón: Tucumán y la región del noroeste. Período 1810-1825, Tucumán, UNT, 2008.

López, Cristina: Los dueños de la tierra. Economía, sociedad y poder en Tucumán (1770-1820), Tucumán, Facultad de Filosofía y Letras, UNT, 2003.

López, Cristina: «El comercio en Tucumán 1810-1815: flujos de mercancías y dinero y balanzas comerciales», en Población y Sociedad, 2, Tucumán, Fundación Yocavil, 1994, 47-79.

López, Cristina: «Comercio de exportación de la jurisdicción de San Miguel de Tucumán: circuitos comerciales y especialización productiva, 1785-1810», Cuadernos de Contexto Andino, 2, Tucumán, Consejo de Investigaciones Científicas y Técnicas de la Universidad Nacional de Tucumán, 1994, 10-35.

López, Cristina: «Redes de parentesco y poder en la frontera de Tucumán: la familia Alurralde, en López, Cristina (comp.): Familia, parentesco y redes sociales, Tucumán, Facultad de Filosofía y Letras, UNT, 2004, 139-174.

López, Cristina: «Revolución, libre comercio e importaciones en Tucumán, 18091819», en: López, Cristina, (Comp.): Identidades, representación y poder entre el Antiguo Régimen y la Revolución. Tucumán, 1750-1850, Rosario, Prohistoria, 2009, 119.

Macias, Flavia y Parolo, Paula: «Guerras de independencia y reordenamiento social. La militarización en el norte argentino (primera mitad del siglo XIX)», Revista Iberoamericana, Alemania, 37, 2010, 19-38.

Marchionni, Marcelo: «Una elite consolidada. El cabildo de Salta en tiempos de cambios», en Mata de López, Sara (comp.), Persistencias y cambios: Salta y el Noroeste argentino. 1770-1840, Rosario, 1999, 181.

Moutoukias, Zacarías: «Familia patriarcal o redes sociales: Balance de una imagen de la estratificación social», en Anuario del IEHS, Buenos Aires, 15, 2000, 55-75.

Nicolini, Esteban: Flujos de mercancías y dinero en Tucumán en la primera mitad del siglo XIX. Aproximación metodológica, Tucumán, Facultad de Filosofía y Letras, UNT, 1994.

Ponce Leiva, Pilar y Arrigo, Amadori: «Redes sociales y ejercicio del poder en la América Hispánica: consideraciones teóricas y propuestas de análisis», Revista Complutense de Historia de América, Barcelona, 34, 2008, 15-42.

Posse, José María: Los Posse. El espíritu de un clan, Buenos Aires, Editorial Sudamericana, 1993.

Saguier, Eduardo: «Genealogía de la tragedia argentina. Auge y colapso de un fragmento de estado o la violenta transición de un orden imperial-absolutista a un orden nacional-republicano (1600-1912)» en línea, http:// www.er-saguier.org/obras/gta/Tomo-III/Seccion-D/Capitulo-16/0-CRS05.pdf, 18, (27 de noviembre de 2008). 


\section{FRANCISCO BOLSI}

Schmit, Roberto: Ruina y resurrección en tiempos de guerra. Sociedad, economía $y$ poder en el Oriente Entrerriano Posrevolucionario, Buenos Aires, Prometeo, 2004.

Terán, Justino: «Los Pondal. Aportes genealógicos», en Centro de Estudios Genealógicos de Tucumán, Boletín, 4, diciembre de 2004, 63.

Timothy, Anna: La caída del Gobierno Español en el Perú. El dilema de la Independencia, Lima, Perú, IEP, 2003. 